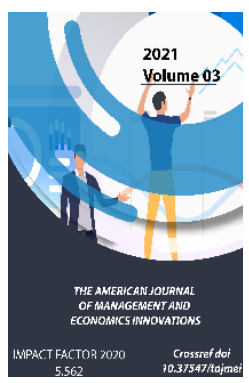

\title{
Scientific Foundation For Implementation Of The Compliance Control System At Corporate Enterprises
}

\author{
Dilmurod Kholmuradovich Suyunov \\ Doctor Of Economics, Head Of The Department, Graduate School Of Business And \\ Entrepreneurship, Uzbekistan
}

Journal Website:

http://theamericanjour

nals.com/index.php/taj

mei

Copyright: Original

content from this work

may be used under the

terms of the creative

commons attributes

4.0 licence.

\section{ABSTRACT}

The article analyzes the concept of compliance control at corporate enterprises, the views of economists in this area, the principles of compliance control, as well as implementation methods. In addition, the article presents scientifically substantiated conclusions on this issuer.

\section{KEYWORDS}

Strategy, transparency, corporate enterprises, compliance, control, corruption, rule, convention, standard, guidance, principle, risk, transparent, sustainable, culture, stakeholder, principle, affiliates.

\section{INTRODUCTION}

The experience of developing the economies of advanced countries demonstrates that with the aim of ensuring efficient management of joint stock companies and raising the market value of the company it is required to provide openness, transparency and compliance with ethical standards and norms, as well as introduction of compliance control. Moreover, introduction of a contemporary cutting-edge control system in the activities of joint stock companies is considered one of the most significant issues. In this regard it should be noted that the Action Strategy for further development of the national economy implies that "...the necessity to introduce updated standards and technique of corporate governance, to strengthen the role of shareholders in the strategic management of enterprises and .... introduction of actual mechanisms of departmental control over the 
prevention and elimination of infringement of rights" is crucially important for solving the problem specified above.

Herewith, the assignment to introduce a "compliance control" system in cooperation with the United Nations Development Program to develop and implement internal anti-corruption measures in ministries, companies and local governments has been set at the meeting of the President of the Republic of Uzbekistan on January 11, 2020 devoted to the issues of combatting corruption and improvement of public control systems.

\section{LITERATURE REVIEW}

The term "compliance" is derived from the English word, which means observing and obeying rules, laws, standards, and policies. In terms of a practical point of view, compliance involves development of a system of internal procedures in the company, measures to control, reveal and prevent violations of laws, rules and standards. However, this term has been considered in various approaches by scholars on economics throughout the world.

Currently the word "compliance" as an economic term is interpreted differently by economists. From the point of view of M.M.Aleshin and Ye.I. Aleshina, "Compliance control" means that the company has competitive advantages and its importance increases year by year. In addition, compliance control as a function constitutes an integral part of corporate governance raises its efficiency, which, in turn, maintains its sustainable development by enhancing the value of the company".
It should be noted that no single interpretation of the term "compliance" has been provided by the scholars-economists, however, taking into consideration English origin of this word, which means "conformity", compliance implies observance of the requirements of any standard or norm. There are different views in the scientific literary sources on the content of the function of the term "compliance", which can be explained as follows:

- It is an integral part of the corporate culture in the company, in which each employee must perform official duties, including decision-making at all levels, in compliance with the standards of legality and integrity established by the company to do its business;

- Never-failing and precise measures to identify the cases and facts of noncompliance with laws and requirements, as well as the regulations, requirements and standards of the market economy and internal statutory acts of the company, including activities related to the improvement of corporate governance;

- The aim of the introduction and management of compliance is to detect and prevent corporate crime and errors, problems, reduce losses for the company, prevent the recurrence of such harmful and hazardous situations, improve business and control processes;

- We consider compliance as a state of compliance between an actor's behavior or norms on one side, precise rules, procedures, conventions, standards, guidelines, principles, legislation or other norms predetermined by others. Although we do not concentrate on more 
comprehensive observance to norms, we admit the principles as the norm, and it is a strict condition which must be followed. A compliance situation can be achieved regardless of the motives, reasons, or circumstances that have caused it. In our opinion, therefore, the actor can obey without mastering the norms and changing his beliefs or behavior. Moreover, inadvertent compliance is also compliance. Finally, compliance must be distinguished from efficiency because it does not have to achieve the appropriate final goals.

In addition, some economists believe that the word "compliance" should be divided into two parts, that is, first, to express the legal compliance of the activity with existing regulations, and second, ethically, to ensure compliance with the company's industry standards and internal regulations used in daily activities.

Compliance control system in companies is based on the requirements of the law in each country and the rules and standards that may vary from company to company, how the company behaves in the services market, observance over ethical rules and international standards, conflict of interest management, being in fair relations with customers, as well as providing a fair approach in rendering advisory services to customers. In addition, the company's shareholders, investors, supervisory board and other stakeholders are interested in the application of "compliance control" in the company's performance. Furthermore, its efficient operation can ensure the effectiveness of corporate governance.
Thus, compliance control is the system that supervises the compliance of the company's activities with the requirements of laws, norms, regulatory requirements, standards and the consequences of non-compliance. In addition, it is aimed at ensuring appropriate advice, and even undertaking measures in reliance upon applicable law. It is the type of activity, which should be considered as a system in which the company's management and employees control the company's conformity with applicable laws, standards, internal and external norms and regulations, and most importantly, intended to combat corruption in the company's activities. To achieve this aim, it is definitely required to adopt relevant public statutory acts combating corruption.

For reference: In this regard Uzbekistan is adopting appropriate statutory acts and regulations. Herewith, on January 3, 2017 the Republic of Uzbekistan adopted the Law № 419 "On combatting corruprtion". This Law implies that corruption, which also applies to the activities of public administration and business entities, is the illegal use of smb's position or position for personal profit or gain of material or intangible benefits for the benefit of others, as well as the illegal provision of such benefits. In addition, it provides some comments that the most common conflict of interest in the activities of joint stock companies is a conflict of personal (direct or indirect) interest between the rights and legitimate interests of citizens, agencies, society or the state, which influences or may influence proper performance of official or authorized duties. Moreover, the Decree of the President of the Republic of Uzbekistan dated May 27, 2019 has set the following objectives: since July 1 compulsory periodic 
assessment of the risks of corruption in the implementation of the tasks and functions assigned to public authorities; since August 1, 2019 as an experiment it is proposed to organize implementation of the "Corruptionfree Sector" project in the field of capital construction and higher education at the initial stage with the involvement of the public and leading experts, including foreign representatives. Furthermore, the State Program approved by this Decree determined such top targets as "Strengthening anticorruption measures in agencies with a state share in the charter capital, including: introduction of a system of "compliance control" to combat corruption and monitor its efficiency; establish certification procedures in compliance with the relevant anti-corruption standard (ISO 37001)".

The basic area (scope of work) of compliance in the company is to combat the misappropriation of financial funds, control over foreign exchange, ensure the accuracy of accounts and reports, conformity of financial statements with international financial reporting standards and conformity of accounting reports with current regulations, and to supervise performance of activities in accordance with customs, banking, antimonopoly, labor, environmental, tax and other types of legislation.

The aim of compliance is to ensure the fact that the company's financial and economic condition does not deteriorate and that it does not lose the trust of the company's top management, shareholders, investors, partners and other stakeholders concerned, as well as and to identify information on the minimum state of risk in all activities. Any financial losses, taxes and sanctions imposed by law enforcement can make a negative impact on further enhancing the company's position. In such cases, it is possible to give an example of the major types of compliance risk:

- Information that makes an impact on a company's reputation. This includes the spread in the media of negative information about the company or its employees, representatives of management, shareholders, affiliates, employees of regulatory authorities;

- The state of affairs of compliance with principles of law. This implies harassment by law enforcement agencies as a result of infringing the requirements of laws and other statutory acts concerning the company's activities;

- Incidents with current risks. Herewith, the company incurs losses as a result of infringing the company's internal regulations. Furthermore, these are violations of legal requirements and decisions of the Board of Trustees of economic entities and internal documents by affiliates and shareholders of the company. Therefore, it is necessary to have a specialized body in the management structure of joint-stock companies, which can work in the field of corruption and risk management. This fact will definitely be required to ensure transparency, openness and investment attractiveness of the company's noncorrupt activities.

In addition, in order to ensure efficiency of the corporate governance system in the company, it is necessary to introduce a corporate governance code that shall determine the business schedule of management bodies, 
ensuring openness and transparency of information and internal control over financial activities and, definitely, compliance.

For reference: Over recent years our country has been consistently implementing largescale comprehensive reforms aimed at preventing and combating corruption, restricting corruption in all areas of state and society building. Moreover, relevant measures are being undertaken to improve the system for assessing the risks of corruption and introduction of standards of honesty in the civil service, elimination of bureaucratic barriers and reduction of the "shadow economy", as well as implementation of "Corruption-free Sector" projects.

To accomplish these objectives, the AntiCorruption agency of the Republic of Uzbekistan (hereinafter referred as the "Agency") was established in accordance with the Decree of the President of the Republic of Uzbekistan PD-6013 as of June 29, 2020. The Agency has been assigned the following objectives: introduction and organization of efficient functioning of internal anticorruption control system ("compliance control") and other international anticorruption tools at the public and economic administration bodies, state enterprises and enterprises with state share in the charter capital, including banks, conducting anticorruption monitoring based on contemporary methods, as well as information and communication technologies, the task of compiling a rating of their activities in this area; conducting administrative inquiries concerning anti-corruption on the compulsory applications submitted on suspension or cancellation of corruption in the decisions of executive local authorities, economic management authorities and the persons concerned; as well as in 2020-2021 gradual introduction of the anti-corruption internal control system ("compliance control") in cooperation with other agencies concerned with the attraction of the funds of international organizations.

\section{RESEARCH METHODOLOGY}

Such research methods as observation, abstract-logical thinking, systematic analysis, comparison and economic interpretation have been widely used in this article.

\section{ANALYSIS AND DISCUSSION OF THE RESULTS}

Therefore, while currently the compliancecontrol system in companies is basically of a risk-specific nature and peculiar to foreign companies, it should be based on certain principles when applied to any enterprise and entity, as well as for government agencies or companies. When introducing a system of compliance control in the joint-stock commercial banking system based on the activities of joint-stock companies, it is recommended to follow the following principles:

In joint-stock companies the first principle of the compliance control system is the principle of responsibility which implies that:

It is the responsibility of the Directors or the Supervisory Board to determine and manage compliance risks and to exercise overall control. The Directors or the Supervisory Board will have to approve the compliance policy of the joint-stock commercial bank, which implements a permanent and efficient compliance function, and evaluate management efficiency in this area at least once a year.

The second principle of the compliance control system is the independence of the 
compliance function, which implies official status: existence of a compliance manager with overall responsibility for coordinating compliance risk management; elimination of the possibility of a conflict of interest between the obligations of employees of the company to perform their functions and other tasks assigned; the fact that company employees have the information they need to perform their duties.

The third principle of the company's compliance control system is the availability of the resources required to ensure efficient performance of its functions and obligations. These resources certainly include financial, economic, legal, labor, and other resources.

The fourth principle of the "compliance control" system in companies is to ensure interaction with internal audit. Herewith, compliance - functions, its area of implementation and scope should be regularly reviewed by the internal audit service.

The fifth principle of the "compliancecontrol" system in companies is implementation of international relations in the company. This determines the use of the company's outsourcing system. That is, the individual assignments of the compliance function can be accepted through outsourcing, but they must be properly supervised by the head of the compliance function. Compliance - risk management should be considered as one of the most essential areas of risk management in the company.

Therefore, in reliance upon the principles of the "compliance control" system in companies, it is possible to determine the following functions. These assignments must ensure the following: first, observance over the requirements of applicable law and internal statutory acts, standards and ethical norms of the company and ensuring their implementation; second, constantly improving the ways to minimize compliance risks in the company; third, ensuring strict adherence to the principles of compliance with major transactions made within the company's activities and their implementation, fourth, intention to retain the value of the company in all relations with the company's partners, eliminating conflicts of interest while maintaining mutual interests of all stakeholders benefited in the company's activities; fifth, creating conditions for company employees and other third parties to provide information on breaches of compliance standards in the company in a confidential or in urgent manner, online and by e-mail; sixth, undertaking tight disciplinary measures for infringing compliance standards by the company's employees, constantly monitoring of the status of the compliance system in the company and providing reports to higher authorities in due time, seventh, combatting corruption in the company, as well as money laundering of proceeds from illegal activities and financing of various antigovernment and anti-terrorist activities; eigth, inviting to various events in the company, regulating the process of receiving and giving gifts, timely delivery of information and data on violations of ethical standards to the appropriate authorities; ninth, favored resolution of conflicts of interest between shareholders, investors and other stakeholders and tenth, non-disclosure of confidential information about the company's financial, economic, labor and other resources, as well as compliance with the established standards for the storage and processing of this information.

\section{CONCLUSION}

In conclusion it should be noted that the "compliance control" system is a complex of all processes related to the company's activities, a number of actions aimed at ensuring compliance with the requirements of all laws and ethical norms, standards, codes, rules, statutory acts and other regulations 
related to the company's activities. Therefore, the experience of companies from developed countries in the implementation of compliance control in the company definitely illustrates that it is necessary to, first of all, render support to the company's top managers, senior management, members of the Management Board and the Supervisory Board, second, provide training and information to the company employees, business partners and others in the field of compliance control system and third, determine the role of the elements of the compliance control system in the business processes. This, in turn, first of all, will definitely ensure doing business in guaranteed and transparent way, second, legality of the activities, as well as the existence of standards and regulations in all areas related to the company's performance, independence, reduction of barriers to access to information about the company, as well as transparency of accounting and reporting, third, it will enhance responsibility of the company's Supervisory Board and executive authorities to the to the property owners (shareholders, investors and other stakeholders), and ensure the fact that all relations are based on the principles of equality and fairness, which, in turn, demonstrates a high level of corporate culture and professionalism.

\section{REFERENCES}

1. Law of the Republic of Uzbekistan №419 “On combatting corruption" dated January 3, 2017.

2. Decree of the President of the Republic of Uzbekistan PD-5729 "On measures to further improve the system of combatting inflation" dated May 27, 2019.

3. Decree of the President of the Republic of Uzbekistan PD-6013 “On the measures for further improvement of the corruption combatting system in the Republic of Uzbekistan" dated January 29, 2020.

4. Decree of the President of the Republic of Uzbekistan PD-4947 “On the Action Strategy for further development of the Republic of Uzbekistan" dated February 7, 2017.

5. Materials of the meeting of the President of the Republic of Uzbekistan devoted to "Issues of combating corruption and improving public control in the Republic of Uzbekistan" dated February 11, 2020.

6. Aleshin M.M., Aleshina E.I. Compliance as a tool to raise the value of a corporation // NUKOVEDENIE Internet magazine Vol. 8, №5 (2016) http://naukovedenie.ru/PDF/48EVN516 .pdf.

7. Bondarenko Y. Efficient management of compliance risks: a systematic approach and critical analysis//Corporate lawyer, 2008, №6. p. 31-34.

8. Belyaev Yu.K. Application of compliance control tools to optimize corporate governance of pharmaceutical companies // Izvestiya USUE, 2013, №1 (45). p. 45-50.

9. Suyunov D.Kh. "International finance and accounting" Scientific online journal of Tashkent Institute of Finance, №3, July, 2020, p. 58-63.

10. Benedek, Petra. (2012). Compliance Management - a New Response to Legal and Business Challenges. Acta Polytechnica Hungarica. 9.

11. Foorthuis, Ralph \& Bos, Rik. (2011). A Framework for Organizational Compliance Management Tactics. Lecture Notes in Business Information 
Processing. 83. 259-268. 10.1007/978-3-

642-22056-2_28.

12. Kopytin D. What is compliance, or we play by the rules // Kadrovik. 2010. № 2 .

13. Letter № 173-T dated November 2, 2007 given to the Russian banks on the basis of the document of the Basel Committee "Compliance and compliance function in banks".

14. Murphy D.E. A 1 USD a Day Compliance and Business Ethics Program: How a Small Business Can Get an Effective Corporate Compliance and Business Ethics Pragma, March 2014 URI.: https// www.corporate complianct.org/Portals/1/PDF/R Resources/complimentary/ CEP rogram Dollar ADayMurphy.RUS_web.pdf//.

15. Suyunov D.H. "The main problems of corporate governance and ways to solve them", EPRA International Journal of Economic Growth and Environmental Issues (EGEI) ISSN:23216247 Impact Factor: 8.007 (SJIF 2020) 202101-13-006137, 9, 1, January, 2021. 